\title{
PENINGKATAN PENGETAHUAN PEMBUATAN GAME DALAM RANGKA PENGENALAN INDUSTRI KREATIF PADA SISWA DI MADRASAH ALIYAH AN-NUR SAMARINDA
}

\author{
Siti Qomariah ${ }^{1}$, Andi Yusika Rangan' ${ }^{2}$, Amelia Yusnita ${ }^{3}$ \\ 1,2Teknik Informatika, STMIK Widya Cipta Dharma \\ ${ }^{3}$ Sistem Informasi, STMIK Widya Cipta Dharma
}

Corresponding Author, Email: sitiqom@wicida.ac.id

\begin{abstract}
(CAKRA) the Indonesian game market in 2018 reached US \$ 1.13 billion or the equivalent of Rp.16 trillion (assuming Rp. 14,000 / US \$). Unfortunately, local games only control 0.2\%. The rest is controlled by foreign-made games. the government must focus on encouraging national game production to become a leading sector to help the national economy. To improve the creative industry in the field of games, community service activities are needed which aim to increase the knowledge of teachers and students in making games with various existing software through training. The software used for the development is construct 2.0 software. The stages carried out in this training are pre-test, provision of training materials, game-making practice, post-test and monitoring of results. community service program activities to increase knowledge of game making in the context of introducing the creative industry by means of training to create new entrepreneurs in the creative industry.
\end{abstract}

Keywords: games, creative industry; software; construct.

\begin{abstract}
Abstrak
Game merupakan industri yang sangat besar saat ini.Menurut data asosiasi IP development, Cipta Kreasi (CAKRA) pasar game Indonesia pada 2018 lalu mencapai US $\$ 1,13$ miliar atau setara Rp 16 triliun (asumsi Rp 14.000/US\$). Sayang game buatan lokal hanya menguasai $0,2 \%$. Sisanya dikuasai game buatan luar negeri. pemerinta harus fokus untuk mendorong produksi game nasional menjadi sektor unggulan untuk membantu perekonomian nasional. Untuk meningkatkan industri kreatif bidang game maka diperlukan kegiatana pengabdian masyarakat yang bertujuan untuk meningkatkan pengetahuan guru dan siswa dalam membuat game dengan berbagai software yang ada melalui pelatihan. software yang digunakan untuk pembuatan adalah software construk 2.0 tahapan yang dilakuakan dalam pelatihan ini adalah pretest, pemberian materi pelatihan,praktik pembuatan game, posttest dan pemantauan hasil. kegiatan program pengabidan masyarakat untuk peningkatan pengetahuan pembuatan game dalam rangka penegenalan industrikreatif dengan cara pelatihan dapat mewujudkan wirausaha baru di bidang industri kreatif.
\end{abstract}

Kata kunci : game, industri kreatif, software, construk.

(C) 2020 Penerbit PS2PM FISIPKUM UNSERA

(C) 2020 Segala bentuk plagiarisme dan penyalahgunaan hak kekayaan intelektual akibat diterbitkannya artikel pengabdian masyarakat ini sepenuhnya menjadi tanggung jawab penulis

Siti Qomariah, Andi Yusika Rangan, Amelia Yusnita. Peningkatan Pengetahuan Pembuatan Game Dalam Rangka Pengenalan Industri Kreatif Pada Siswa Di Madrasah Aliyah An-Nur Samarinda. 


\section{Pendahuluan}

Pondok Pesantren An-Nur adalah sekolah yang didirikan oleh Almarhumah Hj. Noor Asyikin Al Hasyimi seorang mubaligh dan tokoh Wanita NU (Nahdatul Ulama) asal Kalimantan Timur, pada tahun 1995. Beliau adalah ustazah yang gigih menyiarkan Islam dan berusahan membentuk generasi Qur'ani yang beriman, berilmu, beramal serta berakhlakul karimah melalui pembinaan secara pondok pesantren tradisional maupun lembaga pendidikaan formal yang mengacu pada kurikulum terbaru. Pondok Pesantren kini memiliki dua sekolah yaitu Madrasah Aliyah An-Nur (SMA/Sederajat), Madrasah Tsanawiyah An-Nur (SMP/Sederajat). AnNur Sekarang dipimpin oleh bapak Akhmad Hamidi S.PdI. Pondok Pesantren An-Nur memiliki Visi “Terwujudnya Lulusan yang beriman, berilmu, beramal dan berakhlakul karimah". Sedangkan untuk Misinya "Memberikan pendidikan dan penanaman keimanan sesuai dengan ajaran Ahlus Sunnah Wal Jama'ah, Mewujudkan siswa yang unggul dan kompetetif dengan memberikan pelajaran yang seimbang antar pendidikan agama, umum dan penguasaan ilmu teknologi, memberikan pendidikan dan mengarahkan siswa untuk menerapkan Amaliah diri dalam masyarakat, Memberikan pendidikan karakter Islami agar siswa dapat menghargai diri, orang lain, dan masyarakat"

Kurikulum yang digunakan oleh Pondok pesantren adalah kurikulum 2013. Kurikulum 2013 merupakan sebuah pembelajaran yang menekankan pada aspek afektif atau perubahan perilakku dan Kompetensi yang ingin dicapai adalah kompetensi yang berimbang antara sikap, keterampilan, dan pengetahuan, disamping cara pembelajarannya yang holistik dan menyenangkan, pembelajaran TIK (Teknologi,Informasi dan Komunikasi) dihilangkan tetapi dalam proses pengajaran tetap dimasukan unsur pengenal dan pemanfaatan TIK. Pemanfaatan laboratorium masih terbatas untuk pengenalan aplikasi pengolahn kata dan angka, ujian semester dan ujian nasional belum dieksplorasi lebih lanjut untuk meningkatkan kemampuan siswa seperti pembuatan game. Peningkatan Kemampuan bisa dilakukan dengan kegiatan pelatihan, kegiatan pelatihan diharapakan di masa mendatang akan tercipta wirausaha yang mumpuni bidang 
industri keratif seperti developer game (gustaf Leonandri, 2020).

Pemanfaatan perangkat lunak komputer sangat berkontribusi dalam penyelesaian berbagai masalah seperi pengolahan data nasabah di kota mojokerto yakni Gaposi (Ardiantoro \& Rohmah, 2019). selain sebagai penyelesaian berbagai masalah pemanfaatan komputer juga bisa untuk pembuatan game yang berpeluang untuk bersaing di industri kreatif bidang game developer.

\section{Pemanfaatan}

laboratorium komputer masih sebatas pengajaran TIK bidang pengolahan kata dan angka, semantara pemanfaatna komputer sekarang ini bukan hanya pengolahan kata dan angka dalam artian administrative tetapi juga sebagai sarana untuk menciptakan aplikasi atau software seperti game yang banyak digunakan sebagai hiburan atau mengisi waktu luang. Industry kreatif adalah Industri yang berasal dari pemanfaatan kreatifitas, ketrampilan serta bakat individu untuk menciptakan kesejahteraan serta lapangan pekerjaan dengan menghasilkan dan mengeksploitasi daya kreasi dan daya cipta individu (E et al., 2019).
Kesiapan pelaku industri kreatif menjadi faktor kunci dalam menghadapi persaingan dengan industri lain. Namun demikian, teknologi yang menyertai era Industry 4.0 juga memberikan banyak peluang yang bisa dimanfaatkan dalam pengembangan industri kreatif berbasis budaya. (Nugroho, 2019). Game merupakan salah satu media yang dapat digunakan dalam menyampaikan sebuah tujuan. Tujuan yang terdapat dalam game mempunyai macam-macam jenis yaitu pendidikan, hiburan dan simulas. (Martono, 2015). Game merupakan salah satu aplikasi yang banyak digunakan masyarakatyang dapat menjadi sarana pemebelajaran atau sarana hiburan (Dirgantara et al., 2020). Game adalah permainan yang merujuk pada kelincahan intelektual dimanan menampilkan keputusan dan aksi pemainnya. Salah satu software untuk membangung game adalah construk 2. Construct 2 adalah Game Engine barbasis HTML5 yang dikembangkan oleh Scirra Ltd, construct 2 sangat mudah digunakan berbeda dengan pengembangan game (Adiwijaya et al., 2015). Pada umumnya construct 2 memudahkan pengembang game untuk membuat aplikasi 
dengan metode visual progaming, yaitu drag and drop modul yang telah disediakan dengan kebutuhan coding yang minimal. Dengan tool construct 2 memungkinkan siapa saja membuat game tanpa harus memiliki pengalaman pemrograman (Damar, 2015). Hal ini ditujukan terutama untuk para non-programmer yang ingin menciptakan sebuah game secara drag and drop menggunakan editor visual dan berbasis system logika prilaku. Construct 2 selain bias digunakan di windows, juga dapat dijalankan dibanyak platform, seperti Mac, Linux, dan iPad.

Game merupakan industri yang sangat besar saat ini. Menurut data asosiasi IP development, Cipta Kreasi (CAKRA) pasar game Indonesia pada 2018 lalu mencapai US $\$ 1,13$ miliar dimana 99,8\% dikuasai oleh developer asing, sedangkan developer pembuat game dalam negeri hanya $0,2 \%$ saja. Hal ini tentu sangat merugikan keuangan Negara, karena banyaknya uang yang mengalir keluar negeri karna aktifitas bermain game.

Berdasarkan data diatas pentingnya menciptakan banyak developer game yang bias menguasai pangsa pasar nasional yang sangat besar sekali nilai ekonominya. Oleh karena itu diperlukan pelatihan cara membuat game untuk meningkatkan pengetahuan cara membuta game dan mengenai industry kreatif itu sendiri. Pelatihan yang terukur akan membantu dalam menentukan langkah-langkah menciptakan wirausaha baru bidang industri kreatif.

\section{Metode Pelaksanaan}

Kegiatan pengabdian masyarakat yang dilakukan menggunakan metode penelitian terapan dengan tahapan sebagai berikut:

1. Pretest adalah tahapan pertama yang dilakuan dengan memberikan kuisioner pertanyaan-pertanyaan kepada peserta agar menegtahui kemampuan dan pengetahuan dari masing-masing peserta pelatihan

2. Pemberian materi adalaha tahan kedua dimana narasumber pelatihan, penyampaian disesuaikan dengan kemampuan masing-masing dari peserta berdasarkan hasil kuisoner pretest.

3. Praktik adalah tahan ketiga dimana setelah memndapatkan pengetahuan, peserta dibimbing langsung mengimplementasikan pengetahuan 
yang didapat dengan membuat game mengunakan software construk 2

4. Posttest adalah tahap ke empat dimanna kita mengukur tingkat pengetahuan dan kemampuan peserta pelatihan dengan quisioner, apa saja ilmu yang didapat dan apa saja yang bisa mereka buat dengan software coonstruk 2

5. Pemantauan hasil adalah tahapan terakhir dimaman narasumber melakukan penilaian terhadap kemampuan peserta pelatihan dalam membuat gake dengan melihat hasil pekerjaan / hasil praktik peserta.

\section{Hasil dan Pembahasan}

1. Mitra

Madrasah Aliyah An-Nur

Samarinda adalah sekolah yang masih berada di Pondok Pesantren An-Nur yang tidak hanya menerapkan kurikulum untukpondik pesantren tetapi juga kurikulum 2013 dengan salah satu kompetensi yang ingin dicapai adalah kemampuan di bidang TIK, tidak hanya kemampuan mengunakan software aplikasi pengolahan kata dan angka tetapi juga memiliki komptensi lainnnya seperti software apliaski untuk membuat game komputer. Berikut gambar mitra kegiatan pengabdian

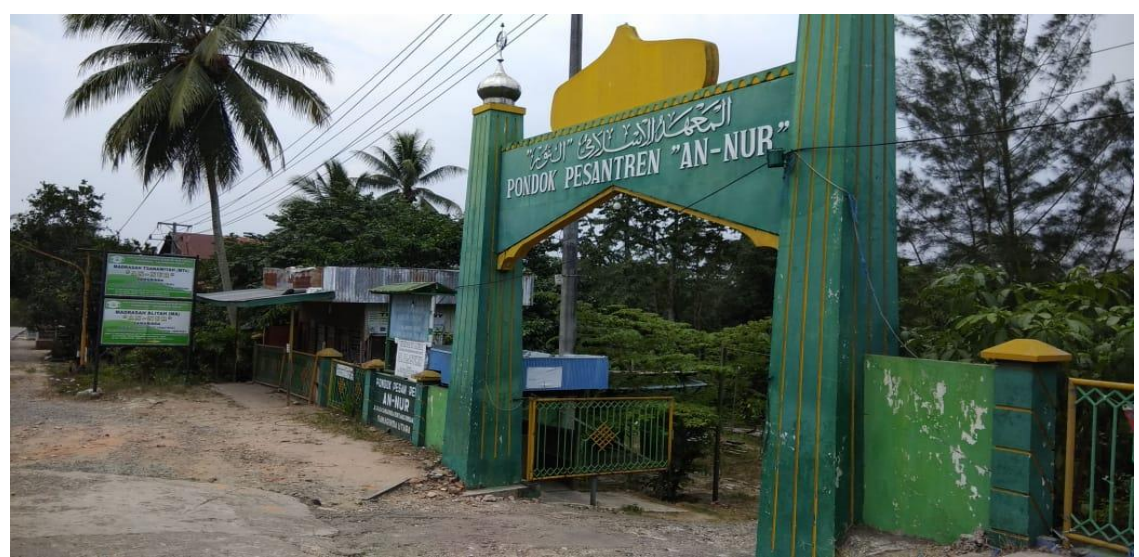

Gambar 1. Tampilan Gapura depan

Jumlah siswa yang terdaftar Ma An-

Nur sebanyak 87 Orang dengan fasilitass pendukung seperti kantin, koperasi, ruang kelas, kantor dan satu laboratorium komputer. Berikut gambar fasilitas lab komputer yang ditunjukan gambar 2 


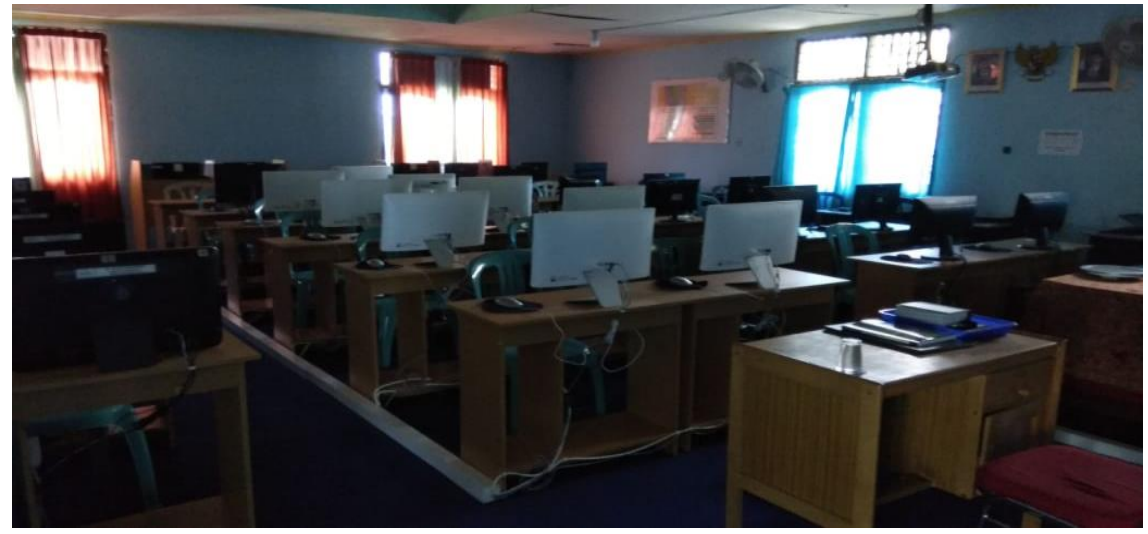

Gambar 2. Fasilitas laboratorium computer

Jarak yang ditempuh dari KM dengan mengunakan kendaraan STMIK Widya Cipta Dharma ke roda empat hal ini terlihat dari Pondok Pesantren An-Nur adalah 9,7 gambar 3 dibawah ini.

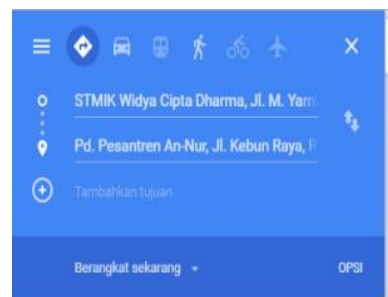

ๆ

melalui J. PM. Noor dan JI. Ahmad $21 \mathrm{mnt}$ Yani//Jl. Bontang - Samarindà DETAL

Gambar 3. Jarak antara lokasi mitra dengan STMIK Widya Cipta Dharma

\section{Pelaksanaan Kegiatan Pengabdian} Kepada Masyarakat

Kegiatan pengabdian masyarakan dilakuan di laboratorium komputer dengan peserta dari siswa dan siswi Madrasah Aliyah An-Nur Samarinda dilaksanakan selama 2 hari dari tanggal 10-11 januari 2020. adapun materi yang diberikan adalah

a) Pengenalan Software Construk b) Pengenalan Storyboard

c) Mendesain game

d) Mengenal coding Programming di construk

e) Convert hasil file construk dalam bentuk android

Dengan tim pelakasana kegiatan adalah Siti Qomariah, S.Kom.,M.Kom selaku Ketua tim yang merupakan dosen 
tetap prodi teknik informatika, Andi Yusika Rangan dosen prodi teknikinformatika selaku anggota 1 dan Amelia Yusnita dosen prodi sistem informasi selaku anggota 2 serta melibatkan mahasiswa yang bernama Nisfa Nanda Putra dari prodi sistem informasi.

Kegiatan pelatihan dilakukan pada hari jumat tanggal 10 Januari 2020 di laboratorium Madrasah Aliyah An-Nur. Diikuti sebanyak 87 peserta. pukul 08.0008.30 kegiatan dibuka oleh bapak Suriansyah, S.Pdi wakil kepala sekolah Ma An-nur yang mewakili pihak sekolah didampingi oleh Siti Qomariah, S.Kom.,M.Kom selaku Kepala P3M STMIK
Widya Cipta Dharma dan Ketua Tim Pengabdian masyarakat. Kemudian dilanjutkan dengan pengisian form Pretest dan kegiata pelatihan.

\section{Evaluasi Kegiatan Pengabdian Masyarakat}

Berdasarkan pelaksanaan kegiatan pengabdian pada masyarakat yang dilakuakan pada tanggal 10-11 Januari 2020 yang dilakuakn oleh dosen dan mahasiswa STMIK Widaya cipta dharma dengan peserta dari siswa dan siswi Madrasah Aliyah An-Nur sangat antusias mengikuti kegiatan tersebut. kegiatan pelatihan dapat dilihat pada gambar 4 . Dibawah ini.

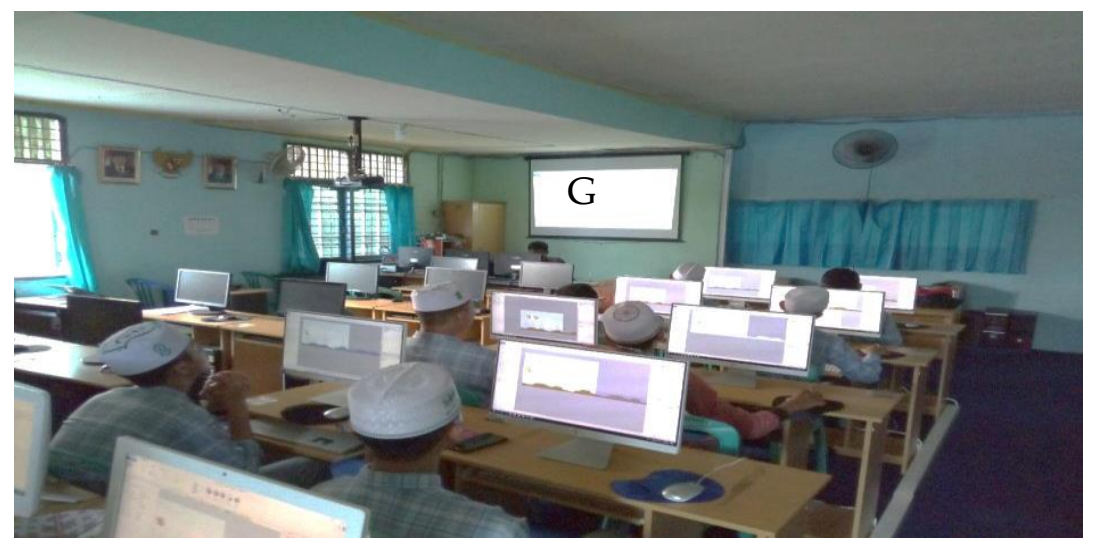

Gambar 4. Kegiatan pelatihan

Kegiatan berjalan lancar dari meningkatkan kompetensi dan kegiatan pembukaan sampai penutupan. mendorong terciptanya para game maker pembuatan game dengan mengunkan baru dalam industri kreatif yang memiliki software Construk sangat bermanfat dalam nilai pasar yang sangat tinggi. adapun 
kendala yang dihadapi adalah tidak semua siswa dapat memahami penjelasan sehingga harus dituntun dengan mendatangi siswa dan menunjukan secara langsung,
Hal ini bisa dipahami karena berdasarkan hasil kuisioner awal dimana tingkat pengetahuan komputer. Berikut grafik tingkat pengetahuan dari peserta

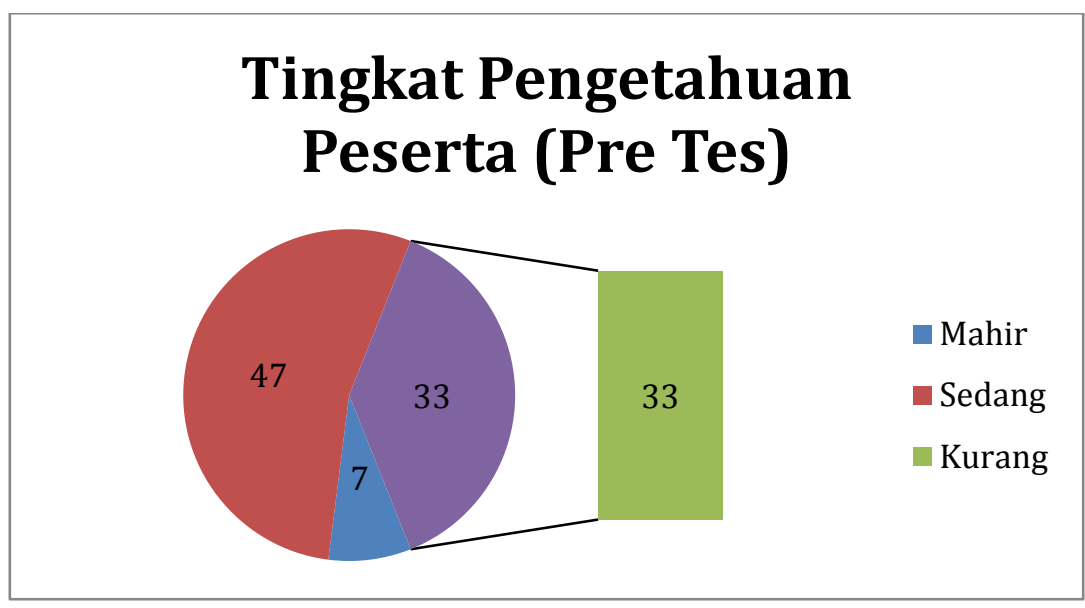

Grafik 1. Tingkat Pengetahuan Peserta (Pre Test)

Setelah dilakukan pelatihan tingkat pengetahuan peserta dari tingkat pengetaua yang kurang sebanyak 33 orang menjadi 18 orang saja. Peserta yang tingkat pengetahuannya berada di level mahir semula berjumlah 7 orang meningkat menjadi 12 orang, data dapat dilihat pada grafik 2 dibawah ini

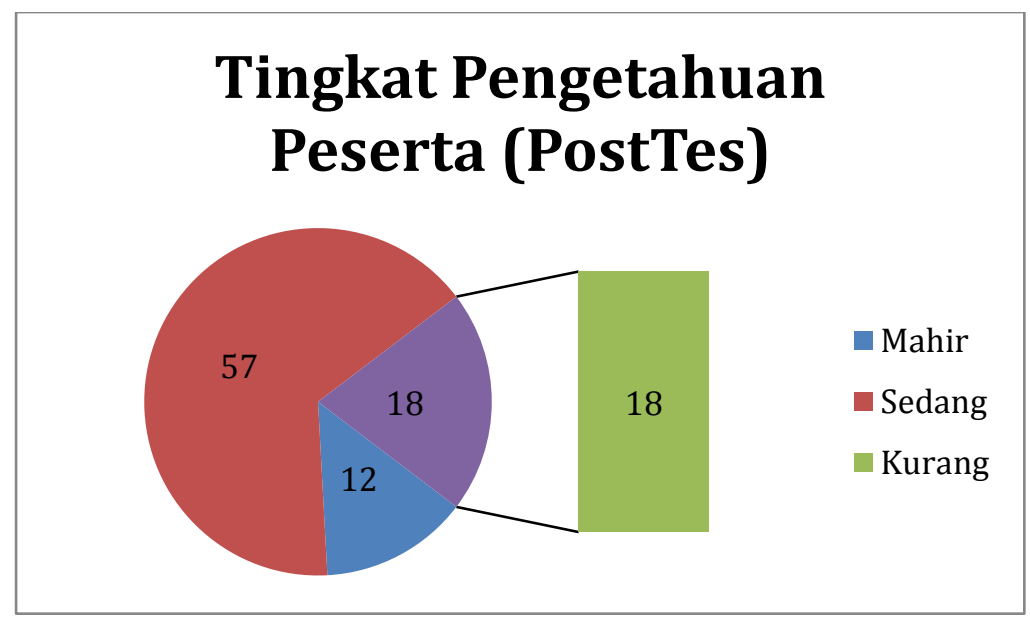

Grafik 2. Tingkat Pengetahuan Peserta (Post Test) 


\section{Simpulan}

Kegiatan Pelatihan dalam rangka kegiatan pengabidan masyarakat yang dilakuakan oleh STMIK Widya Cipat Dharma bekerja sama dengan Madrasah aliyah An-Nur samarinda memberikan pengetahuan mengenai pembuatan game mengunakan software construk serta mengenalkan mengenai industri kreatif dan potensi yang disa didapatkan dari industri ini.

Para peserta sangat antusias dalam mengikuti kegiatan ini, keingintahuan peserta sangat tinggi tetapi terbatas dengan waktu pelatihan yang sedikit sehingga diharapkan kegiatan ini bisa menjadi kegiatan rutin seperti kegiatan ekstrakurikuler. dengan kegiatan yang berlangsung rutin maka akan meningkatkan kemaampuan dan kompetensi siswa dan siswi dalam mengahadapi era industri 4.0

\section{Ucapan Terimakasih}

Kami mengucapkan terimkasih yang sebesar-besarnya kepada STMIK Widya Dharma yang sudah mendukung terlaksananaya kegiatan pengabidan ini serta mitra Madrasah Aliyah An-nur yang mau bekerjasama dalam rangka kegiatan ini.

\section{Referensi}

Adiwijaya, M., S, K. I., \& Christyono, Y. (2015). Perancangan Game Edukasi Platform Belajar Matematika Berbasis Android Menggunakan Construct 2. Transient, 4(1), 128-133.

Ardiantoro, L., \& Rohmah, M. F. (2019). Komputerisasi Untuk Peningkatan Layanan Nasabah Pada Bank Sampah Gaposi Sejahter Mojokerto. BanteneseJurnal Pengabdian Masyarakat, 1(2).

Damar, P. (2015). Bikin Game Tanpa Coding dengan Construct 2. Yogyakarta: Penerbit Andi.

Dirgantara, H. B., Prabowo, Y. D., Kurniawati, Y. E., Windriyani, P., Septanto, H., \& Marselino, T. L. (2020). Pelatihan Pengenalan Game Maker Studio dan. Kalbisabdimas, 3(10), 4547.

E, E., Usman, A., \& Dafitri, H. (2019). Peluang Industri Kreatif Melalui Pelatihan Pembuatan Video Kreatif Bagi Mahasiswa Akademi Dakwah Indonesia Sumatera Utara. Jtunas, 1(1),

https://doi.org/10.30645/jtunas.v1i1.11 Gustaf Leonandri, D. (2020). Meningkatkan Keterampilan Mahasiswa Melalui 
Kegiatan Expert Sharing in Revenue

Management di Politeknik Pariwisata

Palembang. BANTENESE-Jurnal

Pengabdian Masyarakat, 2(1), 42-49.

Martono, K. T. (2015). Pengembangan

Game Dengan Menggunakan Game
Engine Game Maker. Jurnal Sistem Komputer, 5(1), 23-30.

Nugroho, M. T. (2019). Industri Kreatif berbasis Budaya Peluang dan Tantangan di Era Industry 4.0. 